\title{
DESAFIOS DIAGNÓSTICOS DE CHIKUNGUNYA VIRAL EM PACIENTES NEONATAIS: UMA REVISÃO INTEGRATIVA
}

\author{
DIAGNOSTIC CHALLENGES OF CHIKUNGUNYA VIRAL IN \\ NEWBORNS PATIENTS: AN INTEGRATING REVIEW
}

Luiz Custódio Moreira Junior ${ }^{1}$ Thaise de Abreu Brasileiro Sarmento ${ }^{2}$ Renata Braga Rolim Vieira ${ }^{3}$ Aracele Gongalves Vieira ${ }^{4}$ Rodrigo Rufino Pereira Silva ${ }^{5}$

RESUMO: Introdução: O Chikungunya Vírus (CHIKV) é um dos arbovírus transmitidos pelos mosquitos Aedes aegypti e Aedes albopictus que tem sido registrado no continente americano desde julho de 2014. A apresentação clínica dessa patologia é diferente quanto à intensidade dos sintomas em relação aos grupos etários: neonatos, crianças, adultos e idosos. Tendo em vista a dificuldade de se diagnosticar precocemente pacientes recém-nascidos $(R N)$ e devido à sua alta morbidade, torna-se uma importante patologia a ser estudada em termos de saúde pública. Objetivo: Compreender os principais achados clínicos/epidemiológicos de casos suspeitos de Chikungunya viral dentre o grupo dos pacientes neonatais. Método: A pesquisa consta de uma revisão integrativa da literatura. Foram utilizadas as bases de dados da Biblioteca Nacional em Saúde (BVS), Literatura Latinoamericana e do Caribe em Ciências Sociais e da Saúde (LILACS) e National Library of Medicine (PUB-MED) e dos Descritores em Ciências da Saúde (DECS) "Chikungunya Virus", "Infant, Newborn" e "Diagnosis" e suas combinações nos idiomas português, espanhol e inglês e, publicados no período de 2014 a 2018. Resultados: Foram encontrados um total de 127 artigos. Ao utilizar os filtros associados aos critérios de inclusão do trabalho, foram excluídos 57 artigos. Dos 70 artigos elegíveis, 19 foram excluídos após a leitura dos títulos e 32 após a leitura dos resumos. Além disso, foram encontrados dois estudos por meio da busca nos temas referentes e um artigo por meio de busca manual. Três artigos foram excluídos por se encontrarem em duplicata. Ao final 19 artigos foram incluídos na presente revisão

\footnotetext{
${ }^{1}$ Acadêmico de Medicina da Faculdade Santa Maria (FSM), Cajazeiras - PB.

2 Docente do curso de Medicina da Faculdade Santa Maria (FSM), Cajazeiras - PB.

${ }^{3}$ Docente do curso de Medicina da Faculdade Santa Maria (FSM), Cajazeiras - PB.

${ }^{4}$ Docente do curso de Medicina da Faculdade Santa Maria (FSM), Cajazeiras - PB.

${ }^{5}$ Acadêmico de Medicina da Faculdade Santa Maria (FSM), Cajazeiras - PB.
} 
bibliográfica. As infecções pelo CHIKV cursam com um quadro mais grave em lactentes e idosos, e menos grave em crianças e adultos. Os estudos sugerem que a sintomatologia em neonatos é inespecífica para um diagnóstico preciso, tais como febre alta, irritabilidade, inapetência, vômitos, artalgia, edema articular, rigidez cervical, exantema maculopapular não pruriginoso, bolhas e vesículas e cianose de extremidades. A presença da hiperpigmentação leva a uma forte suspeição do diagnóstico da CHIKV. Foi evidenciado, também, que a transmissão vertical perinatal foi principal forma de contágio em neonatos que não foram picados pelos vetores. Porém, o diagnóstico de CHIKV, nesse grupo, também é baseado em aspectos clínicos, epidemiológicos e laboratoriais. Conclusão: Assim, conclui-se que um dos principais métodos utilizados para diagnóstico, a partir dos aspectos clínicos, está em uma anamnese materna detalhada e um estudo específico sobre a epidemiologia local para o vírus. Espera-se, assim, que os resultados obtidos permitam aos profissionais médicos compreenderem a importância de se diagnosticar uma Chikungunya viral em um paciente neonatal, tendo em vista a complexidade que existe para que se chegue a esse raciocínio e que, dessa forma, uma conduta individualizada possa ser realizada.

Palavras chave: Arbovirose; Chikungunya viral; Diagnóstico; Neonatos.

ABSTRACT: Introduction: The Chikungunya virus (CHIKV) is one of the arboviruses transmitted by the Aedes aegypti and Aedes albopictus mosquitoes that has been registered in the American continent since July 2014. The clinical presentation of this pathology is different regarding the intensity of the symptoms in relation to the age groups: newborns, children, adults and the elderly. Considering the difficulty in early diagnosis in the newborns (NB) and due to their high morbidity, it becomes an important pathology to be studied in terms of public health. Objective: To understand the main clinical / epidemiological findings of suspected Chikungunya viral cases among the group of newborn patients. Method: The research consists of an integrative review of the literature. The databases of the National Health Library (VHL), Latin American and Caribbean Literature in Social and Health Sciences (LILACS) and National Library of Medicine (PUB-MED) and Health Sciences Descriptors (DECS)) "Chikungunya Virus", "Infant, Newborn" and "Diagnosis" and their combinations were used, in the Portuguese, Spanish and English languages, and published from 2014 to 2018. Results: A total of 127 articles were found. 57 articles were excluded after the filters associated with the inclusion criteria were used. Of the 70 eligible articles, 19 were excluded after reading the titles and 32 after reading the abstracts. Furthermore, two studies were found by searching the referring subjects and an article was found by manual search. Three articles were excluded because they were duplicated. In the end, 19 articles were included in the present bibliographic review. CHIKV infections are more severe in infants and the elderly, and less severe in children and adults. The studies suggest that symptomatology in neonates is nonspecific for a precise diagnosis, these symptoms include high fever, irritability, inappetence, vomiting, arthralgia, joint edema, cervical stiffness, nonpruritic maculopapular rash, blisters and vesicles, and peripheral cyanosis. The presence of hyperpigmentation leads to a relevant suspicion for CHIKV diagnosis. It was also evidenced that vertical perinatal transmission was the 
main form of infection in newborns who were not bitten by the vectors. However, the diagnosis of CHIKV in this group is also based on clinical, epidemiological and laboratory aspects. Conclusion: Therefore, it is concluded that one of the main methods used for diagnosis, from the clinical aspects, is in a detailed maternal anamnesis and a specific study on the local epidemiology for the virus. So, It is expected that the obtained results allow the medical professionals to understand the importance of diagnosing a viral Chikungunya in a newborn patient, considering the complexity that exists to arrive at this reasoning, and that, in this way, a conduct can be performed.

Keywords: Arbovirose; Chikungunya viral; Diagnosis; Newborns. 


\section{INTRODUÇÃO}

Doenças causadas por vírus transmitidos por artrópodes hematófagos, ou arbovírus, constituem um dos principais problemas de saúde pública em todo o mundo. Os arbovírus são encontrados principalmente nas regiões tropical e subtropical, e na maioria dos casos também causam infecções subclínicas. O Chikungunya Vírus (CHIKV) pertence ao gênero Alphavirus, família Togaviridae, transmitidos pelos vetores, mosquitos Aedes aegypti e Aedes albopictus. Nesse âmbito, o vírus da Dengue compartilha os mesmos vetores, sintomas e distribuição geográfica do Chikungunya. (CALVO et al., 2016; FARUQUE et al., 2017).

Quanto aos primeiros casos registrados da doença, Braga et al. (2017) relata que em meados de 2005/2006 demasiados casos de Chikungunya ocorreram em muitos países onde a Dengue era endêmica, começando no Oceano Índico e Ilhas Indianas e, até 2013, atingindo o hemisfério ocidental da ilha caribenha de São Martinho. Em julho de 2014, o vírus se espalhou para outros 20 países do Caribe e América Central e do Sul, com mais de 500 mil casos relatados em 2016.

Para Burt (2013), na população em geral, apresenta-se clinicamente um início súbito da doença caracterizada por febre alta, artralgia severa e mialgia, juntamente com cefaleia, fotofobia e erupção cutânea em formas de exantemas. As infecções assintomáticas são raras; cerca de 3-25\% de pessoas com evidência sorológica de infecção não tem sintomas óbvios. No entanto, essas infecções se apresentam de forma diferente quanto à intensidade dos sintomas e à sua heterogeneidade, em relação aos diversos grupos etários, cursando com uma sintomatologia mais grave em recém-nascidos $(R N)$ e idosos, e menos grave em crianças e adultos. (DUARTE et al., 2016; CHATTOPADHYAY et al., 2016).

Existem diferenças na apresentação clínica de $\mathrm{RN}$ e adultos com a Chikungunya Vírus. Os neonatos têm um início do quadro de forma abrupta com febre já no primeiro dia, seguido do desenvolvimento de exantema maculopapular. Vesículas e bolhas são mais comumente vistas em população infantil e se 
desenvolvem no quarto dia, assim como a presença de acrocianose e hiperpigmentação que sugerem o Chikungunya vírus como diagnóstico diferencial nesses casos, porém sem alteração hemodinâmicas significantes (VASANI et al., 2016).

Torres et al. (2017) relata que as principais manifestações clínicas e sintomas nos pacientes neonatais são: febre, assim como, em decrescente percentual, irritabilidade, erupções cutâneas, edema generalizado, hiperalgesia, pescoço rígido ou dor à mobilização.

Segundo o Ministério da Saúde (2017), existem grandes riscos de transmissão perinatal em casos onde as mães adquirem o vírus Chikungunya no período intra parto, podendo haver um contágio do vírus ao recém-nascido, principalmente, por via transplacentária, sendo que a transmissão, neste período pode chegar a aproximadamente $50 \%$ desses casos, cerca de $90 \%$ podem evoluir para formas graves da doença.

Dentre o contexto abordado, uma das principais justificativas desse trabalho está na realidade de que o diagnóstico clínico de pacientes neonatais infectados pelo vírus da Chikungunya torna-se um desafio para os profissionais da saúde durante o manejo desses pacientes, tendo em vista que as principais manifestações que acomentem esse grupo podem ser inespecíficas e, muitas vezes, direcionar um diagnóstico errôneo. Essa questão tem sua importancia devido aos crescentes processos epidêmicos que se instalam, nos últmos anos, em diversas regiões do globo, principalmente no continente americano.

Dessa forma, espera-se que informações acerca do tema sejam elucidadas para atingir o público-alvo, profissionais da saúde, e que desse modo, permita a compreensão de todo o processo de diagnóstico destes pacientes com bases nos principais achados clínicos e epidemiológicos, avaliando os possíveis diagnósticos diferenciais e, de uma forma geral, possa impulsionar atividades de controle e prevenção da patologia, assim como, favorecer subsídios para uma conduta individualizada e correta deste grupo de pacientes em estudo. Sendo assim, o estudo tem como objetivo compreender os principais achados clínicos/epidemiológicos de casos suspeitos de Chikungunya viral dentre o grupo dos pacientes neonatais. 


\section{MÉTODO}

Consta-se de um estudo realizado por meio da revisão bibliográfica do tipo integrativa. Em uma revisão integrativa há a necessidade de identificar, analisar e sintetizar resultados de estudos independentes sobre uma temática específica, incluindo estudos experimentais e não experimentais, possibilitando emergir vários aspectos de um mesmo fenômeno. As informações sintetizadas e comparadas possibilitam conclusões gerais em relação à problemática abordada. Sua aplicabilidade se dá não somente pela elaboração de protocolos, procedimentos e políticas, mas também no pensamento crítico que a prática diária necessita (BOTELHO et al., 2011).

Sobre o desenvolvimento da revisão integrativa da literatura, as etapas serem a seguidas constituem-se em seis, a saber: 1- estabelecer a hipótese e questão norteadora; 2- delimitar a amostra a ser estudada, através dos critérios de inclusão e exclusão; 3- selecionar as bases de dados e qualificar os estudos; 4- analisar os estudos inseridos na pesquisa; 5 - interpretar os resultados e 6- apresentar a síntese da revisão (DAL SASSO MENDES; CAMPOS PEREIRA SILVEIRA; GALVÃO, 2008).

A primeira etapa foi orientada por uma indagação, que teve a seguinte questão norteadora: Quais os desafios para o diagnóstico de Chikungunya viral em pacientes neonatais?

$\mathrm{Na}$ segunda etapa, no intuito de se fazer o levantamento bibliográfico, foi procurado, durante o primeiro semestre de 2018, artigos na internet. As bases de dados utilizadas foram a Biblioteca Nacional em Saúde (BVS), Literatura Latinoamericana e do Caribe em Ciências Sociais e da Saúde (LILACS) e National Library of Medicine (PUB- MED). Foram utilizados os Descritores em Ciências da Saúde (DECS): "Chikungunya Virus", "Infant, Newborn", "Diagnosis". Foram utilizadas as associações: Chikungunya Virus AND Infant, Newborn AND Diagnosis. 
Durante 0 rastreio bibliográfico, onde as estratégias utilizadas foram adaptadas segundo cada base de dados e suas peculiaridades, foram utilizados como critérios de inclusão artigos disponíveis e completos; artigos nacionais e internacionais com publicações nos idiomas português, espanhol e inglês; estudos em humanos e publicados no período de 2014 a 2018.

Quanto aos critérios de exclusão, foi levado em consideração: teses, dissertações, monografias, artigos que não corroboram com a temática após a leitura de seus títulos e resumos, artigos que não tenham seus resumos disponíveis e publicações que se repitam nas bases de dados.

\section{RESULTADOS}

Durante o processo de rastreio dos dados, foi encontrado um total de 127 artigos. Ao utilizar os filtros associados aos critérios de inclusão do trabalho: publicações no período de 2014-2018; estudos em humanos; textos completos; línguas portuguesa, espanhola e inglesa, foram excluídos 57 artigos. Dos 70 artigos elegíveis, 19 foram excluídos após a leitura dos títulos, tratando-se de artigos referentes a outras patologias. Após a leitura dos resumos foram eliminados mais 32 artigos, pois esses não apresentavam neonatos dentre os pacientes estudados.

Foram encontrados dois estudos por meio da busca nos temas referentes a uma revisão integrativa de literatura e um artigo por meio de busca manual classificado como guia prático. Três artigos foram excluídos por se encontrarem em duplicata.

Ao final 19 artigos foram incluídos na presente revisão bibliográfica do tipo integrativa, esses artigos continham estudos com população neonatal, infantil e adulta, acometidos pelo CHIKV. A figura 1 apresenta o resumo do processo de seleção dos artigos.

De modo geral, a publicação mais antiga foi de 2014; os artigos são referentes a diversas regiões do globo, desde o nordeste brasileiro ao sudeste asiático. $\mathrm{O}$ delineamento do tipo análise descritiva foi predominante. 
Quanto à forma de avaliação do quadro clínico dos pacientes, observaram-se diversas manifestações, sendo elas típicas e atípicas que levam a suspeita diagnóstica de Chikungunya viral nos pacientes neonatais, estando sempre em análise condições epidemiológicas, clínicas e laboratoriais.

Foi analisado, também, que no referente estudo nem todos os casos foram confirmados por testes laboratoriais, mas sempre por suspeita clínica/epidemiológica e devido a semelhança clínica com outras patologias, os estudos podem ter incluídos crianças cujo diagnóstico de Chikungunya tenha sido feito de forma errônea ou associado a outra arbovirose, assim como lactentes fora do período neonatal. 
Figura 1 - Fluxograma de identificação e seleção dos artigos para revisão integrativa sobre Desafios diagnósticos de Chikungunya viral em pacientes neonatais, 2014 a 2018.

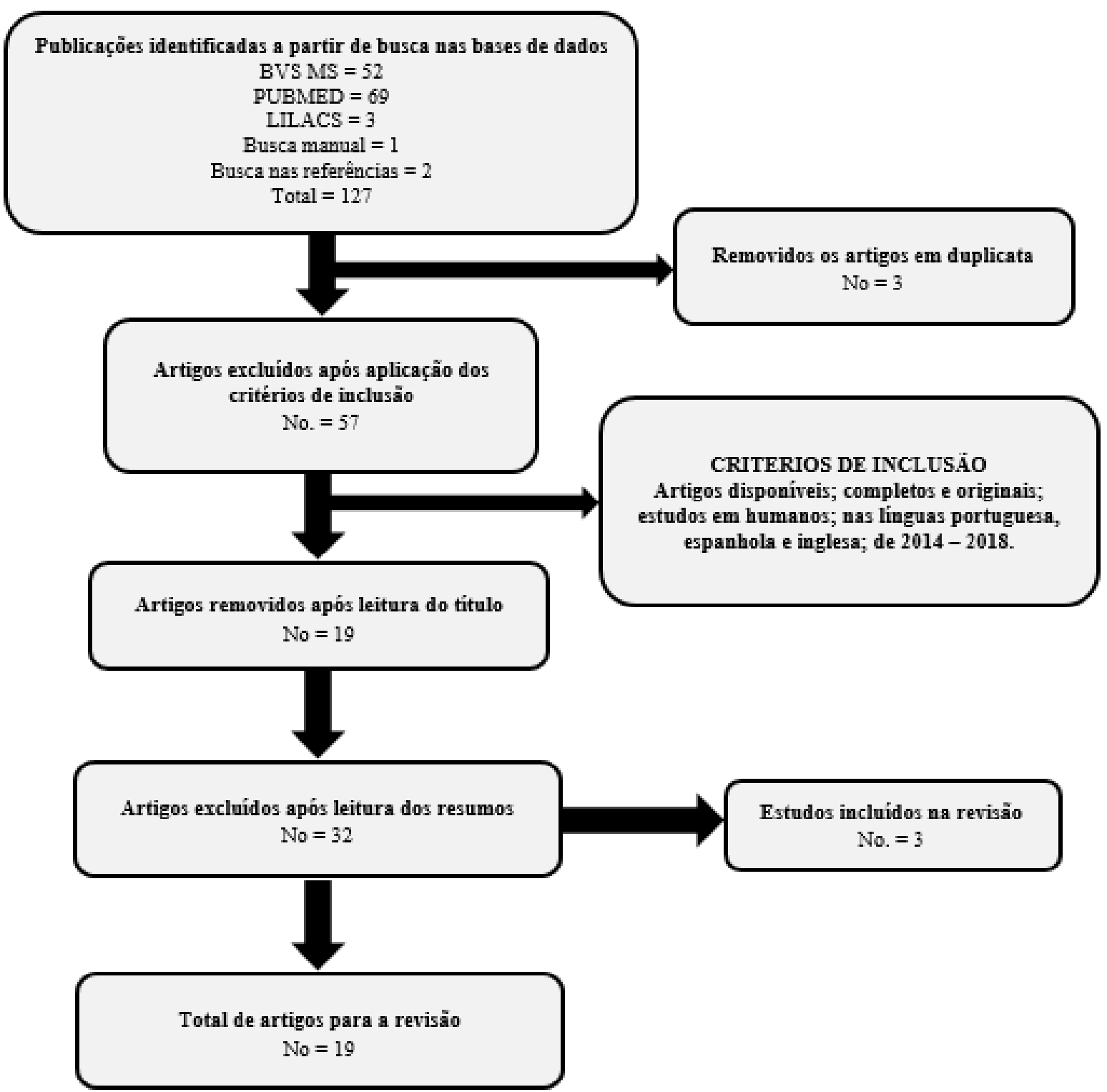

\section{DISCUSSÃO}

Desde meados de 2005 grandes surtos de Chikungunya ocorreram em muitos países onde a Dengue também era endêmica e, a partir de 2014 evadiu-se para 
outros 20 países, incluindo regiões asiáticas e americanas, com mais de 500.000 casos registrados em 2016. Foi evidenciado, então que no Brasil os primeiros relatos autóctones foram confirmados em setembro de 2014 e até a o terceiro trimestre de 2016 já haviam sido registrados 236.287 casos prováveis de infecção pelo vírus, 116.523 confirmados através de métodos laboratoriais sorológicos. As alterações no meio ambiente causadas pelos seres humanos, o crescimento urbano desenfreado e o número cada vez maior de viagens internacionais têm sido ditos como os fatores responsáveis pela reemergência de epidemias em grande escala. (BURT et al, 2013; MARQUES et al, 2017).

O CHIKV possui três fases clínicas: aguda, subaguda, e crônica, sendo que seus sinais e sintomas se apresentam de forma mais intensa entre as crianças e os idosos, embora atinja indivíduos de qualquer idade ou sexo, podendo ser assintomática em menor número de casos e de infecção dificilmente fatal. De uma forma genérica dentre os grupos etários, o período incubatório intrínseco, que ocorre no ser humano, é em média de 3 a 7 dias (podendo variar de 1 a 12 dias, sendo menor na população pediátrica). O extrínseco, que ocorre no vetor, dura em média 10 dias. O período de viremia no ser humano pode perdurar por até 10 dias e, geralmente, inicia-se dois dias antes da apresentação dos sintomas podendo perdurar por mais oito dias. (MORCERFL et al, 2014; MINISTÉRIO DA SAÚDE, 2017).

Segundo Marques et al (2017), os modelos experimentais de artrite induzida por alfavírus sugerem que a patogênese da evolução para a cronicidade da Febre Chikungunya seja resultado de uma combinação de dano celular e tecidual direto, causado por reprodução viral, e indireto, por ativação da resposta imune nos tecidosalvo. Dessa forma, o Chikungunya vírus tem como principais complicações gravidade significativa da doença e mortes ocorridas em sua fase aguda, com possíveis afecções neurológicas. Ao contrário dos outros dois arbovírus, Dengue e Zika, o CHIKV frequentemente resulta em formas crônicas da doença, com cerca de $40 \%$ dos pacientes em fase aguda progredindo para artrite crônica por meses a anos, dados referentes à população não pediátrica. (BRAGA et al, 2017).

As infecções assintomáticas são raras; em média apenas $10 \%$ de pessoas com evidência sorológica de infecção não tem sintomas óbvios. No entanto, essas 
infecções se apresentam de forma diferente quanto à intensidade dos sintomas e à sua heterogeneidade, em relação aos grupos etários: neonatos, crianças, adultos e idosos, cursando com uma sintomatologia mais grave em lactentes e idosos, e menos grave em crianças e adultos, parecendo descrever uma curva em forma de "U" ao que tange a severidade dos sintomas. Embora a doença esteja associada à baixa mortalidade, isso leva a uma alta morbidade e torna-se uma importante patologia a ser estudada em termos de saúde pública. (DUARTE et al., 2016; CHATTOPADHYAY et al., 2016).

Um estudo realizado por Chattopadhyay et al (2016) mostra que dentre um grupo de pacientes neonatais a febre foi o sintoma mais comum em 72 dos 76 casos confirmados. Dor articular esteve presente em 65 casos soropositivos. Os pacientes apresentaram histórico de que a dor teve início no primeiro e no segundo dia de febre. Evidenciou-se, também, envolvimento da coluna, pequenas e grandes articulações de ambas as extremidades, sem predileção de membros superiores / inferiores a partir da manipulação das mesmas. A dor apresentava-se bilateralmente e raramente havia envolvimento unilateral, sem anormalidades radiológicas. As erupções cutâneas foram generalizadas, eritematosas, maculopapulares e não pruriginosas, tanto no tronco quanto nas extremidades, diferindo nesse âmbito da qualidade pruriginosa do exantema das demais arboviroses nos paciente $\mathrm{RN}$, principalmente o Zika vírus (SOUZA et al., 2016). As úlceras aftosas também estavam presentes na mucosa oral e na língua. Os sintomas diminuíam de intensidade de 3 a 5 dias, postergando a dor e o inchaço das articulações.

A partir de outro estudo realizado pelas instituições latino americanas, Hospital Nacional de la Mujer e Hospital Nacional Zacamil, Torres et al. (2017) relata que em um grupo de 169 pacientes neonatais com infecção pelo CHIKV, confirmados sorologicamente (55 casos) e suspeitos (114 casos), foram descritas como principais manifestações sintomáticas: febre (100\%), irritabilidade e inapetência (90\%), erupção cutânea (84\%), edema generalizado (86\%), hiperalgesia (94\%), rigidez do pescoço ou dor ao mobilizar (38\%), instabilidade hemodinâmica e hematológica, esses em decrescente percentual de aparição. Em outro estudo feito no estado brasileiro de Pernambuco, Ramos et al. (2017) evidencia a dificuldade de se diagnosticar um paciente perinatal infectado pelo CHIKV a partir da 
sintomatologia geral: febre, irritabilidade e prostração, quando de um relato de caso com diagnóstico errôneo de sepse neonatal e tratamento intensivo com uso de antibióticos de amplo espectro sem evidências de melhoras clínicas. Nesse mesmo caso, a anamnese materna e a história de manifestações agudas da Febre Chikungunya, dois dias antes do parto, direcionaram uma investigação no paciente recém-nascido sendo comprovado a infecção pelo CHIKV após confirmação através do método ELISA IgM positivo para o mesmo.

Em pacientes neonatais, estima-se que a artalgia esteja presente em $78 \%$ dos casos e, na maioria deles, acompanhada por edema articular distal. Da mesma forma, o exantema é polimorfo, rubeoliforme ou roseoliforme, tratando-se dos sinais clínicos cutâneos mais frequentes nesse grupo, porém, relatos recentes descrevem a hiperpigmentação facial (Nariz brownie) associado à trombocitopenia em pacientes infectados recém-nascidos pelo CHIKV. (LATORRE, 2015).

A presença da hiperpigmentação leva a uma forte suspeição do diagnóstico da CHIKV e suas principais localizações são em região central da face, tronco e ombros, podendo persistir por semanas a meses. Da mesma forma, as lesões vesicobolhosas são observadas mais frequentemente em recém-nascidos e podem aparecer quatro dias após o início da doença, podendo está associadas à trombocitopenia, linfopenia e aumento leve a moderado de enzimas hepáticas também são frequentes. (INSTITUTO OSWALDO CRUZ, 2018).

Para Latorre (2016), a transmissão materno-fetal pode acontecer durante a gravidez (congênita) ou mesmo na fase de lactação pós-natal, porém essas formas são raras, sendo a infecção perinatal a principal forma de contágio em neonatos que não foram picados pelos vetores. A infecção materna se espalha para o embrião ou feto de forma ascendente da vagina e do colo do útero para o líquido amniniótico e sangue devido à viremia, parasitemia ou bacteremia.

Dessa forma, evidências de sérias consequências da transmissão vertical do CHIKV para o feto têm sido relatadas, particularmente associada a febre hemorrágica e encefalopatia. Casos de prematuridade, morte fetal, baixo peso ao nascer, anormalidades fetais, e sofrimento fetal agudo, são descritos na literatura apenas associados ao vírus da Dengue. Os casos em que as mães foram infectadas pelo vírus da Chikungunya durante a fase intraparto tornam-se um sinal de alarme já 
que o risco para transmissão é considerável, assim como, o risco de complicações a partir da forma grave da doença, não associado ao tipo de parto, seja ele natural ou cesário. (SOUZA et al., 2016; MINISTÉRIO DA SAÚDE, 2016).

Gérardin et al. (2016), afirma que o envolvimento do sistema nervoso central foi relatado em um terço dos pacientes em seu estudo. Esses relatos manifestaramse como edema cerebral maciço a partir de ressonância magnética, estando este edema associado a aumento da permeabilidade da barreira hematoencefálica, porém sem dano direto do vírus no SNC.

O diagnóstico pela infecção por CHIKV em neonatos também é baseado em aspectos clínicos, epidemiológicos e laboratoriais, porém após a fase aguda da doença o diagnóstico é baseado em métodos sorológicos $\lg \mathrm{M}$ e $\lg \mathrm{G}$, podendo ser utilizado nos centros mais modernos os métodos de isolamento viral e RT-PCR. Dessa forma, o grande desafio para um sistema de vigilância epidemiológica onde os três vírus Dengue, Zika e Chikungunya, circulam simultaneamente é a detecção inicial de casos em uma epidemia baseada na identificação de um quadro clínico compatível com a definição de um caso suspeito. (LATORRE, 2016; BRAGA et al., 2016; GÁLAN-HUERTA et al., 2015). 
Figura 2 - Critério diagnóstico da infecção por VCHIK

Critérios

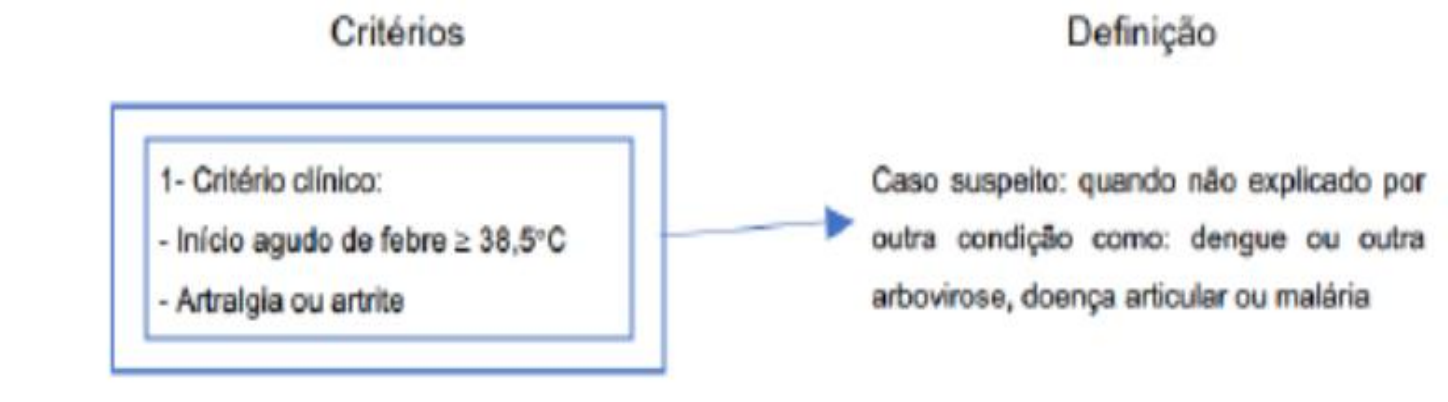

Caso provável: apresentam criterios dinioos e epidemiológicos, mas outros patógenos com manifestação cinica similar estâo co-circulando na mesma região geográfica

Caso oonfirmado: Se um dos testes do critério laboratorial foi positivo independente das manifestaçob dinicas

- IgM positiva

$.4 x \circ$ aumento lg $G$ em amostras paresdas

Fonte: adaptado, Burt et al., 2012.

\section{CONCLUSÃO}

Os estudos evidenciaram que os principais sintomas relacionados à infecção pelo CHIKV são inespecíficos, podendo ser encontrados em outras patologias nessa faixa etária, tais quais podem ser listados como: febre alta, irritabilidade, inapetência, vômitos, artalgia, edema articular, rigidez cervical, exantema maculopapular não pruriginoso, bolhas e vesículas e cianose de extremidades, necessitando-se, dessa forma, de um diagnóstico diferencial com outras doenças exantemáticas. As complicações neurológicas, como encefalite, meningite e síndromes convulsivas 
foram vistas, porém, em alguns casos, como complicações tardias. Assim, conclui-se que um dos principais métodos utilizados para diagnóstico, além dos testes laboratoriais sorológicos, está em uma anamnese materna detalhada e realizada com exatidão, assim como um estudo específico sobre a epidemiologia local para o vírus.

Dessa forma, os neonatos de mães que foram infectadas pela CHIKV durante o período intraparto devem receber monitorização adequada na tentativa de se evidenciar sinais clínicos precoces da doença. Em casos de maior risco da infecção, esses pacientes devem ser internados em unidades de cuidados intensivos para avaliações constantes de parâmetros hematológicos e testes sorológicos.

Espera-se, diante da pesquisa, que os resultados obtidos pela análise bibliográfica permitam aos profissionais médicos compreenderem a importância de se diagnosticar uma Chikungunya viral em um paciente neonatal, tendo em vista a complexidade que existe para que se chegue a esse raciocínio e que, dessa forma, uma conduta individualizada possa ser realizada. 


\section{REFERÊNCIAS BIBLIOGRÁFICAS}

BAQUERO-LATORRE, Hernando. La fiebre de Chikungunya en el período neonatal. Salud, Barranquilla, Barranquilla, v. 31, n. 3, p. 642-650, Dec. 2015.

BOTELHO, L. L. R.; DE ALMEIDA CUNHA, C. C.; MACEDO, M. O método da revisão integrativa nos estudos organizacionais. Gestão e sociedade, v. 5, n. 11, p. 121-136, 2011.

BRAGA, J. U. et al. Accuracy of Zika virus disease case definition during simultaneous Dengue and Chikungunya epidemics. Ng LFP. PLoS ONE, 2017. Disponível em: < https://www.ncbi.nlm.nih.gov/pmc/articles/PMC5484469/>. Acesso em: 01 de março de 2018.

BRASIL. Mistério da Saúde (MS). Secretaria de Vigilância em Saúde Departamento de Vigilância das Doenças Transmissíveis. Chikungunya: Manejo Clínico. Brasília, 2 ed., Versão eletrônica, 2017.

em:

<http://portalarquivos.saude.gov.br/images/pdf/2016/dezembro/25/chikungunya-novo-

protocolo.pdf >. Acesso em: 04 de março de 2018.

BRASIL. Instituto Oswaldo Cruz. Programa de Pós-Graduação em Medicina Tropical. Febre Chikungunya Em Gestantes E Recém-Nascidos: Revisão Sistemática Da Literatura E Relato De Casos No Estado Do Rio De Janeiro. Programa de Pós-Graduação em Medicina Tropical. Rio de Janeiro Março de 2018. Disponível em: <https://www.arca.fiocruz.br/handle/icict/26855>. Acesso em: 15 de novembro de 2018.

BURT, F.; RULLI, N.; HEISE, M. T. Chikungunya: A re-emerging virus. Lanced. África do Sul, 2013. Disponível em: < https://sci-hub.tw/10.1016/S0140-6736(11)60281-X>. Acesso em: 02 de março de 2018.

CALVO, E. P. et al. Diagnóstico diferencial de dengue y chikungunya en pacientes pediátricos. Revista Biomédica. Bogotá: v. 16, 2016. Disponível em: <https://www.revistabiomedica.org/index.php/biomedica/article/view/2982>. Acesso em: $27 \mathrm{de}$ fevereiro de 2018.

CHATTOPADHYAY, S. et al. Chikungunya virus infection in West Bengal, India. Brief Communication, West Bengal, v. 34, 2016. Disponível em: $<$ http://www.ijmm.org/article.asp?issn=0255-

0857; year $=2016$; volume $=34 ;$;ssue $=2 ;$ spage $=213$; epage $=215$; aulast=Chattopadhyay $>$. Acesso em: 01 de março de 2018.

DAL SASSO MENDES, K.; CAMPOS PEREIRA SILVEIRA, R.C.D; GALVÃO, C. M. Revisão integrativa: método de pesquisa para a incorporação de evidências na saúde e na enfermagem. Texto \& contexto enfermagem, v. 17, n. 4, 2008.

DUARTE, M. D. C. M. B. et al. Chikungunya infection in infants. Ver. Bras. Saude matern Infant, 2016. Disponível em: http://www.scielo.br/scielo.php?script=sci_arttext\&pid=S151938292016000800006. Acesso em: 02 de março de 2018.

FARUQUE, L. et al. Prevalence and clinical presentation of Rickettsia, Coxiella, Leptospira, Bartonella and chikungunya virus infections among hospital-based febrile patients from December 2008 to November 2009 in Bangladesh. BMC Infectious Diseases. Bangladesh, 2017. Disponível em: <https://www.ncbi.nlm.nih.gov/pubmed/28193163>. Acesso em: 01 de março de 2018. 
GALÁN-HUERTA, K. A; RIVAS-ESTILLA, A. M; FERNÁNDEZ-SALAS, I; FARFAN-ALE J. A, RAMOSJIMÉNEZ, J. Chikungunya vírus: A general overview. Medicina Universitaria, v. 17, n. 68, p. 175-183, 2015. Acesso em: 15 de novembro de 2018.

GÉRARDIN, P. M. D. et al. Chikungunya virus-associated encephalitis: A cohort study on La Réunion Island, 2005-2009. American Academy of Neurology. 2015. Disponível em: <https://sci-hub.tw/10.1212/WNL.0000000000002234>. Acesso em: 04 de março de 2018.

MARQUES, C. D. L. Recomendações da Sociedade Brasileira de Reumatologia para diagnóstico e tratamento da febre chikungunya. Parte 1 - Diagnóstico e situações especiais. Revista Brasileira de Reumatologia. v. 57, p. 421-437, 2017. Acesso em 15 de novembro de 2018.

MORCERFI, C.C.P. et al. Chikungunya: arbovirose como problema de saúde em expansão uma revisão bibliográfica. Revista Rede de Cuidados em Saúde. 2014. Acesso em: 15 de novembro de 2018.

RAMOS, R. M. D. et al. Perinatal Chikungunya Virus-Associated Encephalitis Leading to Postnatal-Onset Microcephaly and Optic Atrophy. The Pediatric Infectious Disease Journal. Publish Ahead of Print, 2017. Disponível em: <https://scihub.tw/10.1097/INF.0000000000001690>. Acesso em: 04 de março de 2018.

SOUZA, A. S. R. Ultra-som intra-uterino alterado, crescimento do perímetro cefálico fetal e resultados neonatais entre os casos suspeitos de síndrome congênita do zika no Brasil. Revista Brasileira de Saúde Materno Infantil Versão on-line. Recife. v.16, 2016. Disponível em: http://dx.doi.org/10.1590/1806-9304201600s100002. Acesso em 15 de novembro de 2018.

TORRES, J. R. et al. Congenital and perinatal complications of chikungunya fever: a Latin American experience. International Journal of Infectious Diseases. v. 51, Pages 85-88, 2016. Disponível em: <http://www.ijidonline.com/article/S1201-9712(16)31166-3/fulltext>. Acesso em: 04 de março de 2018.

VASANI, R. M. D. et al. Congenital Chikungunya-A Cause of Neonatal Hyperpigmentation. Pediatric Dermatology. Maharashtra: v. 33, 2016. Disponível em: <https://scihub.tw/10.1111/pde.12650 >. Acesso em: 04 de março de 2018. 